\title{
Synthesis, antioxidant and cathepsin D inhibition activity of quaternary ammonium chitosan derivatives
}

\author{
Wenjuan Li, Yunfei Duan, Jianying Huang ${ }^{*}$, Qunxiong Zheng ${ }^{*}$ \\ Key Laboratory of Fruits and Vegetables Postharvest and Processing Technology \\ Research of Zhejiang Province, College of Food Science and Biotechnology, Zhejiang \\ Gongshang University, Hangzhou 310018, P. R. China
}

Abstract: Two (2-hydroxypropyl) trimethyl ammonium and/or imidazole-based quaternary ammonium chitosan derivatives (NHT-chitosan and Im-OHT-chitosan) were synthesized by using nucleophilic substitution reaction. These two synthesized chitosan derivatives were characterized by Fourier transform infrared spectroscopy, NMR spectra, and UV-visible spectra. The applications as antioxidant agents and cathepsin D inhibitors were further investigated. Both of quaternary ammonium chitosan derivatives exhibited good antioxidant activity upon scavenging against hydroxyl radical and hydrogen peroxide as well as the lipid peroxidation inhibition in the linoleic acid emulsion system. They also exhibited good inhibition activity of cathepsin D protease. NHT-chitosan and Im-OHT-chitosan are potential the natural, healthy and safe preservatives in food industry. Keywords: Chitosan; Quaternary ammonium; Imidazole; Antioxidant activity; Cathepsin D inhibitor.

\footnotetext{
"Corresponding author: Tel: 86-571-2887-7777, E-mail:huangiy@zjgsu.edu.cn, zhengqunxiong@zjgsu.edu.cn.
}

(C) 2015. This manuscript version is made available under the Elsevier user license http://www.elsevier.com/open-access/userlicense/1.0/ 


\section{Introduction}

Postharvest animal and fish meat are highly perishable due to its biological composition. The spoilage of meat usually results from biological reactions, such as oxidation of lipids, the loss of protein functionality, and other reactions caused by the endogenous enzymes and exogenous microorganisms.

The most common strategy to extend shelf life of fresh meat is the use of antimicrobial and antioxidant additives of synthetic origin (butylated hydroxylanisole (BHA), butylated hydroxyltoluene (BHT), and tertiary butylhydroquinone (THBQ)), which are being questioned due to an increasing consumer demand for natural, healthy and safe preservatives. In meat industry, nitrates are commonly used in meat preservation because they not only help kill bacteria, but produce a characteristic flavor and give meat a pink or red color via breaking down in the meat into nitric oxide (NO), which then binds to the iron atom in the center of myoglobin's heme group, reducing oxidation (Harikumar et al., 1974). Nitrates also cause ir-reversible inhibition of chicken muscle cathepsin D via the formation of oxidative species such as nitrous acid, nitric oxide, and nitrogen dioxide (Harikumar et al., 1974). However, the use of nitrates in food preservation is controversial due to the potential harm resulted from the formation of nitrosamines when nitrates are present in high concentrations and the meat is cooked at high temperatures.

With a growing concern on the global environment and public heath problems, numerous studies have focused on natural ingredients for food preservation. Chitosan is an important biocompatible, biodegradable, broadly antimicrobial, nutritional, and antioxidative polycationic polymer obtained from waste shell of the crab, shrimp, and 
crawfish industries. It has been approved as a food additive in Japan since 1983, also applied as a food preservative and as a component of packaging material to improve the quality and shelf-life of food (Vasilatos \& Savvaidis, 2013). Edible films based on chitosan with or without basil or thyme essential oils were studied on the storage and it was demonstrated that these films could maintain quality of pork meat products due to the antioxidant and antimicrobial properties of chitosan (Bonilla et al. 2014). Chitosan with high molecular weight was commonly dispersed in an acetic acid solution at $1 \%$ $(\mathrm{v} / \mathrm{w})$ when it was used as bio-preservative agents in food and medicinal fields because of its insolubility in water. However, cathepsin D, which was considered to be one of most important endogenous proteases in postmortem degradation of muscle, is rather active at this acidic condition (pH 3.0 to 4.5) (Schwartz \& Bird, 1977). That is to say, when high molecular weight chitosan/acetic acid solution was used as preservative, the activity of cathepsin D could, in vivo, potentially aid in the postmortem degradation of myofibrillar proteins to form the decomposition products, such as water-soluble peptides and amino acids, and further produce some harmful ingredients, such as amines, hydrogen sulfide, phenol, indole, fecal olfactory element, and curing alcohol, thus influencing meat tenderness and quality. Furthermore, increasing the $\mathrm{pH}$ of post rigor meat produced more tender cooked meat, similar to fresh meats (Alarcon-Rojo \& Dransfield, 1995).

Therefore, numerous efforts have been devoted to preparing functional derivatives by chemical modification of chitosan to increase its solubility in water and to improve the antimicrobial and antioxidant activities, while remaining the biodegradability and biocompatibility (Rabea et al., 2003). Various functional groups, including alkyl (Zavaleta-Aveja et al., 2014), carboxymethyl (Liu et al., 2007), saccharides or 
oligosaccharides, cyclodextrins, acids, as well as polyacrylic groups (Alves \& Mano, 2008; Belalia et al., 2008; Calero et al., 2010; Chao et al., 2004; Curcio et al., 2009; Harte, 2010; Huang et al., 2011; Liu, 2014; Sashiwa et al., 2004; Siripatrawan \& Kumar et al., 2004; Sobahi et al., 2014; Vachoud et al., 2001; Xie et al., 2002; Zavaleta-Aveja et al., 2014), have been introduced to ameliorate the properties of chitosan.

With the exception of bacterial spoilage, deterioration in quality during storage of meat products occurs by the action of hydrolytic enzymes in the products, so it should be considered to necessitate inactivation of the hydrolases during meat curing processes. Although the treatment with chitosan or chitosan derivatives could efficiently extend the shelf life of various fresh meats, rather few investigations on the inhibition activity of cathepsin D were involved.

It is known that $N$-methyl imidazole has been used as a caramel food coloring in the beverage industries, and imidazole groups presented in the structures of various natural or synthetic drug molecules have anticancer (Congio et al., 2008), antimicrobial (Aridoss et al., 2006; Nagarapu et al., 2008), antioxidant (Smith \& Reeves, 1987), and enzyme inhibition (Siddiquee et al., 2007; Reddy et al., 2015) activities. Therefore, to combine both the advantages of imidazole groups and chitosan and to acquire new water-soluble chitosan derivatives, we designed two quaternary chitosan derivatives, (2-hydroxy-3trimethylammonium)propyl-based and imidazole-based chitosans. Herein, we reported the synthesis, characterization and biological activities of these two water-soluble chitosan derivatives. Their biological activities were systematically investigated by the assessment of hydrogen peroxide $\left(\mathrm{H}_{2} \mathrm{O}_{2}\right)$ scavenging activity, $\beta$-carotene-linoleate bleaching assay, hydroxyl radical scavenging activity, as well as the inhibition ability to 
cathepsin D, as important indicators to achieve natural, healthy and safe food biopreservative agents.

\section{Materials and methods}

\subsection{Materials}

Chitosan with the deacetylation of $96.1 \%$ and the centipoise viscosity of $20 \mathrm{mPa} \cdot \mathrm{s}$ $\left(1 \%, 20^{\circ} \mathrm{C}\right)$ was purchased from Ningbo Zhenghai Haixin Biological Products Co., Ltd. (Zhejiang, China). Cathepsin D from bovine spleen (C 3138) was purchased from Sigma (America). Bovine haemoglobin was bought from TCI (Japan). Other reagents and solvents were purchased from Aladin Reagent Co., Ltd. (Shanghai, China), and used directly without further purification.

2.2 Preparation of $N$-(3-chloro-2-hydroxypropyl)trimethyl ammonium chitosan chloride (1) (Scheme 1)

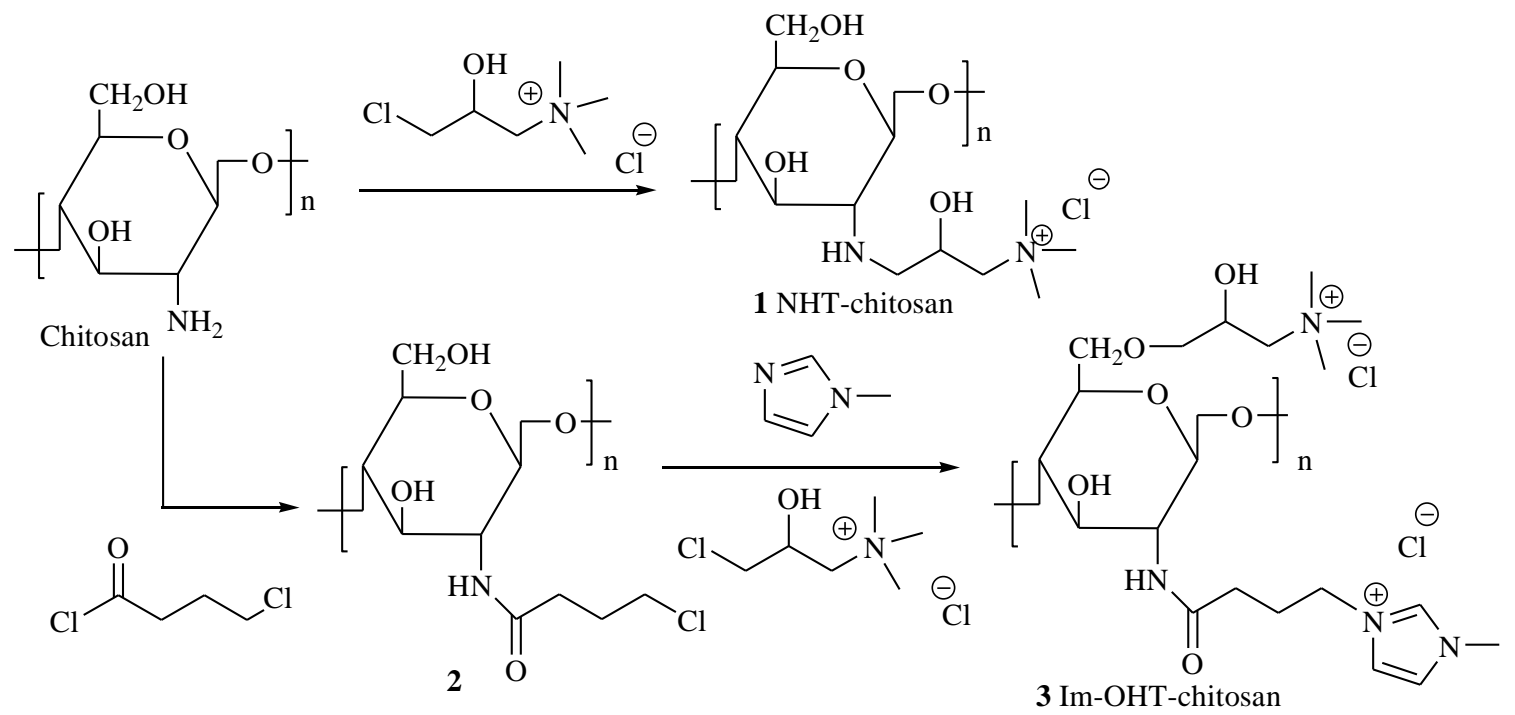

Scheme 1. Synthesis of $N$-(2-hydroxy-3-trimethylammonium)propyl chitosan chloride (1), $\mathrm{N}$-chlorobutyryl chitosan (2) and $\mathrm{N}$-(carboxybutyl-4-(3-methyl-imidazole))-6-O-(2hydroxy-3-trimethylammonium)propyl chitosan chloride (3).

According to our previous report (Zhang et al., 2012), $20 \mathrm{~mL}$ of 2-propanol dispersion solution containing chitosan $(2.00 \mathrm{~g})$ was stirred for $0.5 \mathrm{~h}$ at room temperature, 
followed by adding aqueous $\mathrm{NaOH}(5.00 \mathrm{~g}, 40 \mathrm{wt} \%)$. After stirring for $2 \mathrm{~h}$, (3-chloro-2hydroxypropyl) trimethyl ammonium chloride (CTA) $(10.7 \mathrm{~g}, 57.1 \mathrm{mmol})$ was added to the mixture. The mixture was further stirred for $6 \mathrm{~h}$ at $40{ }^{\circ} \mathrm{C}$. The resulting reaction mixture was then washed with $95 \%$ ethanol to afford a white ropy solid. After filtration, the solid was dissolved in water $(100 \mathrm{~mL})$. The mixture was filtered to remove insoluble gel-like particles. The filtrate was then purified by the addition of anhydrous ether with stirring. The white solid was collected and dried overnight under vacuum at $80{ }^{\circ} \mathrm{C}$ to afford N-(3-chloro-2-hydroxypropyl) trimethyl ammonium chitosan chloride (1) (1.26 g). 2.3 Preparation of $\quad \mathrm{N}$-(carboxybutyl-4-(3-methyl-imidazole))-6- $O$-(2-hydroxy-3trimethylammonium)propyl chitosan chloride (3) (Scheme 1)

Chitosan $(2.00 \mathrm{~g})$ was dissolved in $60 \mathrm{~mL}$ of $N$-methylpyrrolidone (NMP) under nitrogen. $200 \mu \mathrm{L}$ of 4-chlorobutyryl chloride dissolved in $5 \mathrm{~mL}$ of NMP was added dropwise to the above solution. After stirring on room temperature for $3 \mathrm{~h}$, the resulting polymer was precipitated with diethyl ether, followed by washing with methanol and diethyl ether to afford $N$-chlorobutyryl chitosan (2). Compound 2 was then stirred in 200 $\mathrm{mL}$ of $N$-methyl-imidazole under nitrogen at $80{ }^{\circ} \mathrm{C}$ for $72 \mathrm{~h}$. After diethyl ether was added to precipitate the chitosan derivative, the crude product was washed subsequently with methanol and diethyl ether, and dried in a freeze-dryer to give $N$-(1-carboxybutyl-4-(3-methyl-imidazole) chitosan chloride. Then this product $(1.00 \mathrm{~g})$ and $10 \mathrm{~mL}$ of isopropanol were mixed, the mixture was stirred for $0.5 \mathrm{~h}$ at room temperature. Aqueous sodium hydroxide $(\mathrm{NaOH})(2.50 \mathrm{~g}, 40 \mathrm{wt} \%)$ was then added and the mixture was further stirred for $2 \mathrm{~h}$. CTA $(5.37 \mathrm{~g}, 28.5 \mathrm{mmol})$ was added into the resulting mixture and the mixture was reacted for $6 \mathrm{~h}$ at $40{ }^{\circ} \mathrm{C}$. The resulting reaction mixture was cooled to room 
temperature. Anhydrous ethanol was then added dropwise to precipitate the product. After filtration, the residue was dissolved in water $(100 \mathrm{~mL})$, and filtered to remove insoluble solid. The resulting chitosan derivative, $N$-(carboxybutyl-4-(3-methylimidazole))-6-O-(2-hydroxy-3-trimethylammonium)propyl chitosan chloride (3) was obtained $(0.61 \mathrm{~g}$, white solid) after lyophilization of the filtrate.

Characterization. ${ }^{1} \mathrm{H}$ and ${ }^{13} \mathrm{C}$ NMR Spectra were recorded at $343 \mathrm{~K}$ on a Bruker AVANCE DRX 500. FT-IR spectra were recorded on a Nicolet Nexus 870 spectrometer with KBr pellets. UV-visible spectra were recorded on a UV-vis spectrophotometer (UV-2550, Shimadzu, Japan).

The degree of quaternization substitution (DS) of compound (3) was determined by ${ }^{1}$ H NMR integration with Eq. 1 (Sajomsang, Tantayanon, Tangpasuthadol, \& Daly, 2010). $D Q(\%)=(\mathrm{Ar} / \mathrm{n}) /[\mathrm{H} 2+1 / 3 \mathrm{NHAc})] \times 100$

Where DQ $(\%)$ is the quaternization of $N$-substitution, Ar is the integral area of aromatic protons, $\mathrm{n}$ is the number of aromatic hydrogen atoms per-substituent, $\mathrm{H} 2$ is the integral areas of the protons at the $\mathrm{C}-2$ carbon of GlcN, and NHAc is the integral area of GlcNAc protons.

Molecular weight distributions were measured on a conventional gel permeation chromatography (GPC) system equipped with a LC-20AD HPLC pump, a DGU-20A degassing system, a RID-20A RI detector, a 100F-LC injector, a Shodex SUGAR KS-804 linear chromatographic column in a CTO-20A thermostatic oven and LC-solution software. GPC measurements were carried out at $60{ }^{\circ} \mathrm{C}$ using an ultrapure water solution as the eluent with a flow rate of $1.0 \mathrm{~mL} / \mathrm{min}$. The system was calibrated with Pullulan standards. 


\subsection{Assay of $\mathrm{H}_{2} \mathrm{O}_{2}$ scavenging activity}

The $\mathrm{H}_{2} \mathrm{O}_{2}$ scavenging activity was measured according to the literatural method (Zhang et al., 2012). An aliquot (1 mL) of the sample solution $(2 \mathrm{mg} / \mathrm{mL})$ and $0.6 \mathrm{~mL}$ of $\mathrm{H}_{2} \mathrm{O}_{2}(0.043 \mathrm{~mol} / \mathrm{L})$ solution were mixed with $2.4 \mathrm{~mL}$ of phosphate buffer $(0.1 \mathrm{~mol} / \mathrm{L}, \mathrm{pH}$ 7.4). The mixture was shaken vigorously and the absorbance at $230 \mathrm{~nm}$ of the reaction mixture was immediately recorded from 0 to $240 \mathrm{~min}$ at room temperature. For each sample, phosphate buffer without addition of hydrogen peroxide was used for background subtraction. All samples were assayed in triplicate. The $\mathrm{H}_{2} \mathrm{O}_{2}$ scavenging activity was calculated as follows Eq. (2):

Scavenging activity $(\%)=\left[1-\frac{\left(\mathrm{A}_{0}-\mathrm{A}_{\mathrm{x}}\right)}{\mathrm{A}_{0}^{\prime}-\mathrm{A}_{\mathrm{x}}^{\prime}}\right] \times 100$

Where $A_{0}^{\prime}$ is the initial absorbance of control; $A_{0}$ is the initial absorbance of sample; $A_{x}^{\prime}$ is the absorbance of control and $A_{x}$ is the absorbance of sample at different times. $2.5 \beta$-Carotene-linoleate bleaching assay

The ability of chitosan and quaternary chitosans to prevent bleaching of $\beta$-carotene was determined according to the method described by Amin et al. (Amin et al., 2004). 1 $\mathrm{mL}$ of $\beta$-carotene solution $(1 \mathrm{mg} / \mathrm{mL}$ in chloroform) was mixed with $20 \mu \mathrm{L}$ of linoleic acid and $200 \mu \mathrm{L}$ of Tween 20. After stirring at room temperature for 5 minutes, chloroform was removed completely under vacuum in a rotary evaporator at $40{ }^{\circ} \mathrm{C}$. Then $200 \mathrm{~mL}$ of distilled water was added slowly, and the resulting mixture was stirred vigorously to form an emulsion.

$2 \mathrm{~mL}$ of sample solution with different concentrations ranging from 0 to $2.0 \mathrm{mg} / \mathrm{mL}$ dissolved in distilled water were transferred to different test tubes containing $2 \mathrm{~mL}$ of 
emulsion. $2 \mathrm{~mL}$ of emulsion with $2 \mathrm{~mL}$ of distilled water was used as control. Tubes were then gently shaken and placed in a water bath at $50{ }^{\circ} \mathrm{C}$ for $2 \mathrm{~h}$. The absorbance of samples and control was measured at $470 \mathrm{~nm}$ and recorded at $30 \mathrm{~min}$ intervals. All samples were assayed in triplicate. Antioxidant activity was measured in terms of successful bleaching of $\beta$-carotene using Eq. (3):

$$
\operatorname{AoxA}(\%)=\left[1-\frac{A_{0}-A}{A_{0}^{\prime}-A^{\prime}}\right] \times 100
$$

Where $\mathrm{A}_{0}^{\prime}$ is the initial absorbance of control, $\mathrm{A}_{0}$ is the initial absorbance of sample,

$\mathrm{A}^{\prime}$ is the absorbance of control and A is the absorbance of sample after 2 hours.

2.6 Hydroxyl radical scavenging activity

The hydroxyl radical scavenging activity was measured according to the previous report (Liu et al., 2014). The reaction mixture containing $1 \mathrm{~mL}$ of ferrous sulfate (9 $\mathrm{mmol} / \mathrm{L}), 1 \mathrm{~mL}$ of salicylic acid-ethanol $(9 \mathrm{mmol} / \mathrm{L})$, and $1 \mathrm{~mL}$ of sample with various concentrations $(0-2.0 \mathrm{mg} / \mathrm{mL})$ was initiated by $1 \mathrm{~mL}$ of hydrogen peroxide $(0.3 \%, \mathrm{v} / \mathrm{v})$. After incubating and shaken vigorously at $37^{\circ} \mathrm{C}$ for $0.5 \mathrm{~h}$, the absorbance of the reaction mixtures was measured at $510 \mathrm{~nm}$. All samples were assayed in triplicate. The hydroxyl radical scavenging activity was calculated as the following formula:

$$
\text { Scavenging activity }(\%)=\left[\frac{1-\left(\mathrm{A}_{1}-\mathrm{A}_{2}\right)}{\mathrm{A}_{0}} \times 100 \%\right]
$$

Where $A_{0}$ is the absorbance of the control (water instead of sample), $A_{1}$ is the absorbance of the sample, and $\mathrm{A}_{2}$ is the absorbance of the sample only (salicylic acidethanol solution instead of $\mathrm{FeSO}_{4}$ and $\mathrm{H}_{2} \mathrm{O}_{2}$ solution). 


\subsection{Inhibition activity of cathepsin D}

Effect of chitosan derivatives on the cathepsin D activity was investigated according to previous literatures (Esumi et al., 1980; Krause et al., 2011; McLay, 1980) with slight modifications. Acid-denatured haemoglobin substrate $(1.5 \mathrm{~g})$ was dissolved in $150 \mathrm{~mL}$ of sodium acetate buffer $(0.05 \mathrm{~mol} / \mathrm{L}, \mathrm{pH} 3.5)$, following by filtration to remove insoluble particles. Cathepsin $\mathrm{D}(0.5 \mathrm{~mL}, 0.05 \mathrm{mg} / \mathrm{mL})$ and chitosan sample $(0.5 \mathrm{~mL})$ with different concentration were mixed in the presence of $1.5 \mathrm{~mL}$ of sodium acetate buffer $(0.05 \mathrm{~mol} / \mathrm{L}$, $\mathrm{pH} 3.5$ ), subsequently incubated for 10 minutes at $45^{\circ} \mathrm{C}$. Then, $1.8 \mathrm{~mL}$ of haemoglobin solution $(1 \% \mathrm{w} / \mathrm{v})$ (equilibrated to the assay temperature for 10 minutes) was added to the resulting enzyme-chitosan mixture solution. After incubation for 30 minutes at $40{ }^{\circ} \mathrm{C}$ with vigorously stirring, the reaction was terminated by the addition of $2.15 \mathrm{~mL}$ trichloroacetic acid $(\mathrm{TCA})$ solution $(10 \% \mathrm{w} / \mathrm{v})$. The mixture was centrifuged $(10000 \times \mathrm{g}$, $10 \mathrm{~min}$ ) (3-30 K, Sigma). The supernatant was transferred to a quartz cuvette and the absorbance was measured at $280 \mathrm{~nm}$ using a UV-vis spectrophotometer. The blank sample was prepared similarly but contained $0.5 \mathrm{~mL}$ sodium acetate buffer $(0.05 \mathrm{~mol} / \mathrm{L}$, $\mathrm{pH} 3.5$ ) instead of the chitosan solution. Effect of chitosan derivatives on the cathepsin D activity was calculated by the difference in absorbance of the chitosan derivatives sample and the blank. The cathepsin D inhibition constant $\left(K_{\mathrm{i}}\right)$ of chitosan derivatives was determined by using a Lineweaver-Burk and Double-Dixon plot. All analyses were carried out in triplicate.

\subsection{Statistical analysis}

The data were analyzed using analysis of variance (ANOVA) $(\mathrm{P}<0.05)$. The mean differences were established via the Duncan's multiple range tests. The data were 
analyzed by SPSS software (Version 18.0, SPSS Inc., Chicago, IL).

\section{Results and discussion}

3.1 Synthesis. As shown in Scheme 1, chitosan is a chemical structure including intrinsic oxygen- and nitrogen-based functional groups which can serve as the starting points for covalent modification, thereby giving chitosan derivatives with improved properties. In this study, 4-chlorobutyryl chloride was successfully introduced to the primary amino groups of chitosan, followed by reacting with $\mathrm{N}$-methyl imidazole to afford (1carboxybutyl-4--(3-methyl-imidazole) chitosan chloride. The target quaternary ammonium compound $\mathrm{N}$-(carboxybutyl-4-(3-methyl-imidazole))-6-O-(2-hydroxy-3trimethylammonium)propyl chitosan chloride was then obtained by further coupling with $\mathrm{N}$-(3-chloro-2-hydroxypropyl) trimethyl ammonium chloride. It is noteworthy that the purification procedure is quite simple, just by washing with anhydrous ether.

3.2 UV-Vis Spectra. The UV-vis absorptions of chitosan, NHT-chitosan and Im-OHTchitosan are shown in Figure 1. An obvious band at $267 \mathrm{~nm}$ was observed, which is attributed to Im-OHT-chitosan due to $n \rightarrow \pi^{*}$ and $\pi \rightarrow \pi^{*}$ of imidazole ring, while pristine chitosan and NHT-chitosan without imidazole group were transparent in this region because there are no chromophores in the structures of both pristine chitosan and NHTchitosan. 


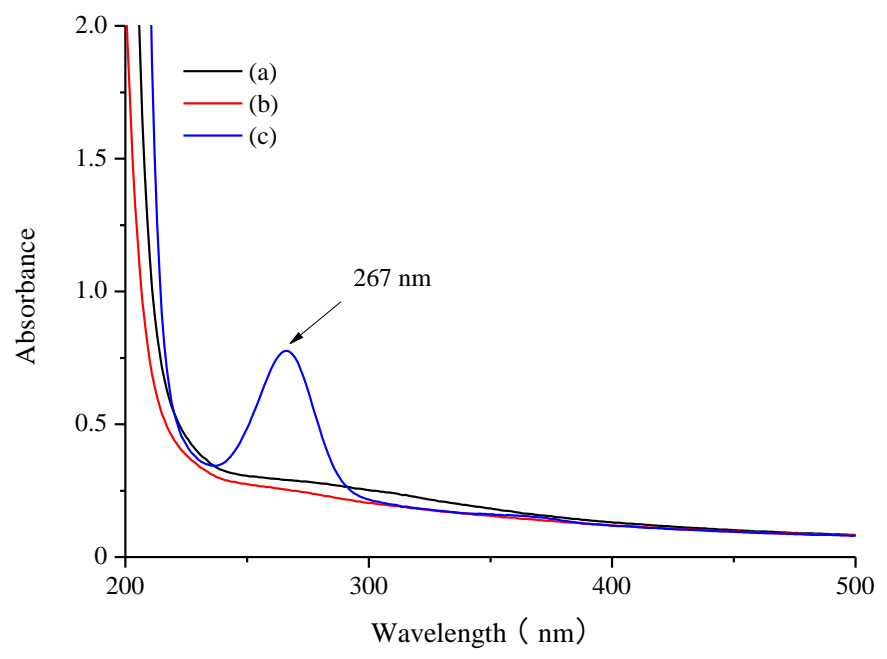

Figure 1. UV-vis spectra of (a) chitosan, (b) NHT-chiosan, (c) Im-OHT-chitosan.

3.3 FT-IR Spectroscopy. The resulting quaternary polymers were characterized using FTIR. As shown in Figure 2, The FT-IR spectrum of (a) chitosan showed the characteristic $\mathrm{C}=\mathrm{O}$ stretching (amide I) bands at $1654 \mathrm{~cm}^{-1}, \mathrm{~N}-\mathrm{H}$ angular deformation band of amino groups at $1584 \mathrm{~cm}^{-1},-\mathrm{CH}_{2}$ bending vibration at $1420 \mathrm{~cm}^{-1}, \mathrm{C}-\mathrm{H}$ (in plane) bending at $1364 \mathrm{~cm}^{-1}$, and amide III band at $1428 \mathrm{~cm}^{-1}$, as well as the band at $1080 \mathrm{~cm}^{-1}$ corresponding to the $\mathrm{C}-\mathrm{O}$ stretching (primary alcoholic groups). The $\mathrm{C}-\mathrm{N}$ stretching band is observed at $1155 \mathrm{~cm}^{-1}$. The broad band at $3419 \mathrm{~cm}^{-1}$ corresponds to $-\mathrm{OH}$ and -NH stretching absorption, whereas the aliphatic $\mathrm{C}-\mathrm{H}$ symmetric and asymmetric stretching band can be observed at $2875 \mathrm{~cm}^{-1}$. The successful NHT-chitosan formation by the reaction of chitosan with (3-chloro-2-hydroxypropyl)trimethyl ammonium chloride can be proved by the disappeared characteristic amide $(\mathrm{C}=\mathrm{O})$ stretching band at $1654 \mathrm{~cm}^{-1}$ and $1584 \mathrm{~cm}^{-1}$ compared to pristine chitosan (a), implying that the epoxide groups of CTA have coupled with the $\mathrm{NH}_{2}$ groups rather than the $\mathrm{OH}$ groups of chitosan (Nam,Kim, \& Ko, 1999; Zhang et al., 2012). The secondary amide groups in the 
backbone of NHT-chitosan displayed a characteristic absorption peak at $1628 \mathrm{~cm}^{-1}$, while a peak at $1399 \mathrm{~cm}^{-1}$ is attributed to the characteristic symmetric absorption of $-\mathrm{CH}_{3}$ bending, suggesting that CTA was introduced to the backbone of chitosan. The FTIR spectrum of Im-OHT-chitosan in Figure 2(c) shows an intermediate peak at $1686 \mathrm{~cm}^{-1}$, which was attributed to the stretching vibration of the characteristic $\mathrm{C}=\mathrm{C}$ group of the imidazole, indicating the successful couple between imidazole and (1-carboxybutyl-4-(3methyl-imidazole) chitosan chloride chain. a peak at $1616 \mathrm{~cm}^{-1}$ corresponded to the $\mathrm{N}-\mathrm{H}$ bending. Additionally, the absorption peaks at $1462 \mathrm{~cm}^{-1}$ and $1393 \mathrm{~cm}^{-1}$ were the bending vibration of $\mathrm{C}-\mathrm{H}$, which were attributed to the $\mathrm{CH}_{3}$ of $\mathrm{N}$-methyl-imidazole and $\mathrm{CH}_{3}$ of CTA, respectively.

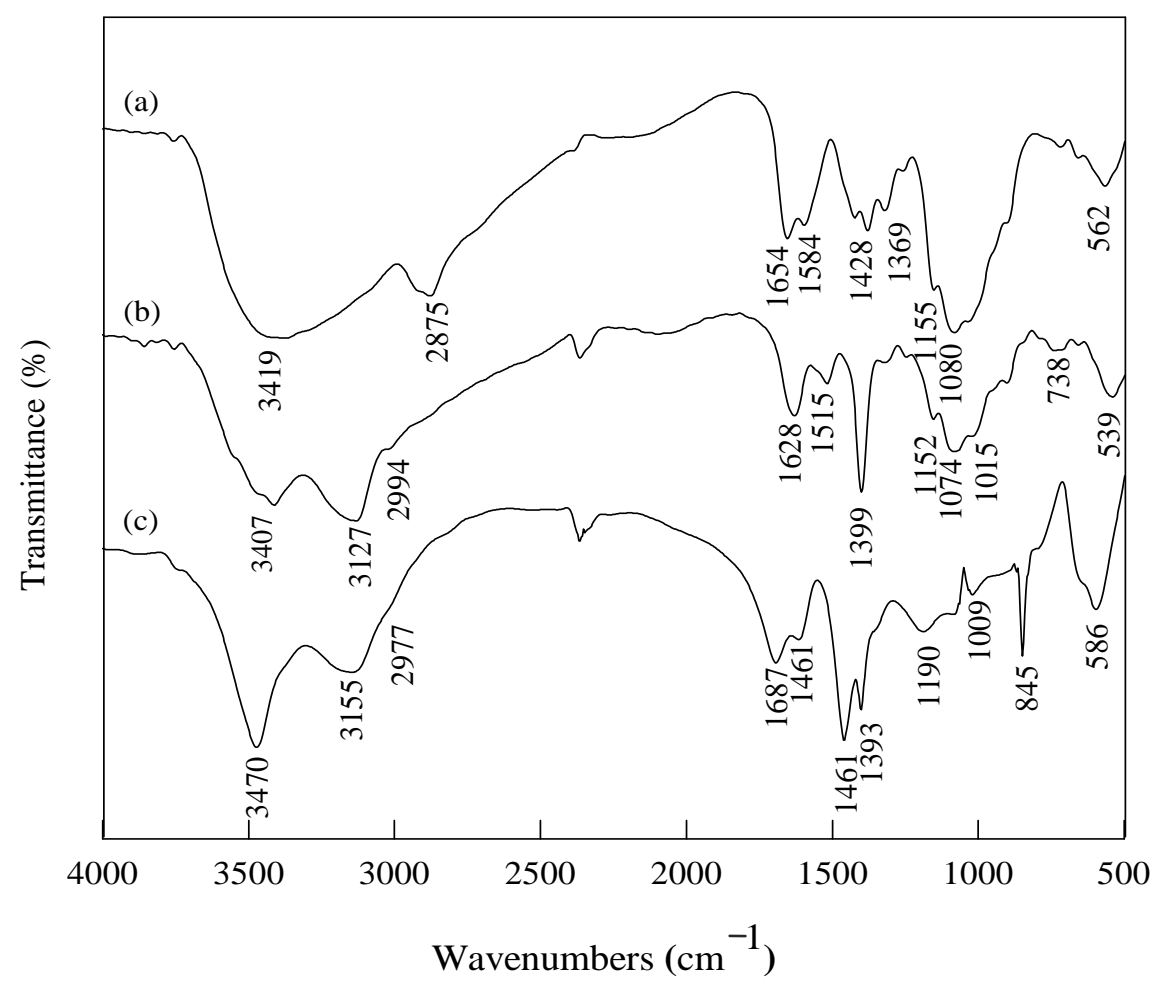

Figure 2. FT-IR spectra of (a) chitosan, (b) NHT-chitosan, (c) Im-OHT-chitosan. 
3.4 NMR Spectroscopy Analysis of Im-OHT-chitosan. The ${ }^{1} \mathrm{H}$ NMR and ${ }^{13} \mathrm{C}$ NMR spectra of Im-OHT-chitosan in $\mathrm{D}_{2} \mathrm{O}$ are shown in Figure 3. Peaks at $3.77 \mathrm{ppm}, 3.66 \mathrm{ppm}$, and multiplet from 3.14 to $3.03 \mathrm{ppm}$ correspond to the methine and methylene protons of glucosamine which are characteristic of chitosan. New signal at $8.07 \mathrm{ppm}$ is attributed to the $\mathrm{N}=\mathrm{CH}$ of imidazolium, while the signal at $5.98 \mathrm{ppm}$ corresponds to $\mathrm{CH}=\mathrm{CH}$ of imidazolium, and the singlet peaks at $2.80 \mathrm{ppm}$ and $2.90 \mathrm{ppm}$ are attributed to methyl from CTA and $N$-methylimidazole, respectively. With the calculation based on the ${ }^{1} \mathrm{H}$ NMR integration data and according to Eq. 1, the degree of quaternization substitution (DS) of compound (3) was determined to be $36 \%$. As shown in ${ }^{13} \mathrm{C}$ NMR spectra (Figure 3), the signals at $\delta 168.7 \mathrm{ppm}, 168.4 \mathrm{ppm}$, and $130.8 \mathrm{ppm}$ are ascribed to the carbons of imidazole, while the peak at $171.6 \mathrm{ppm}$ is attributed to the carbon of carbonyl in glucosamine.

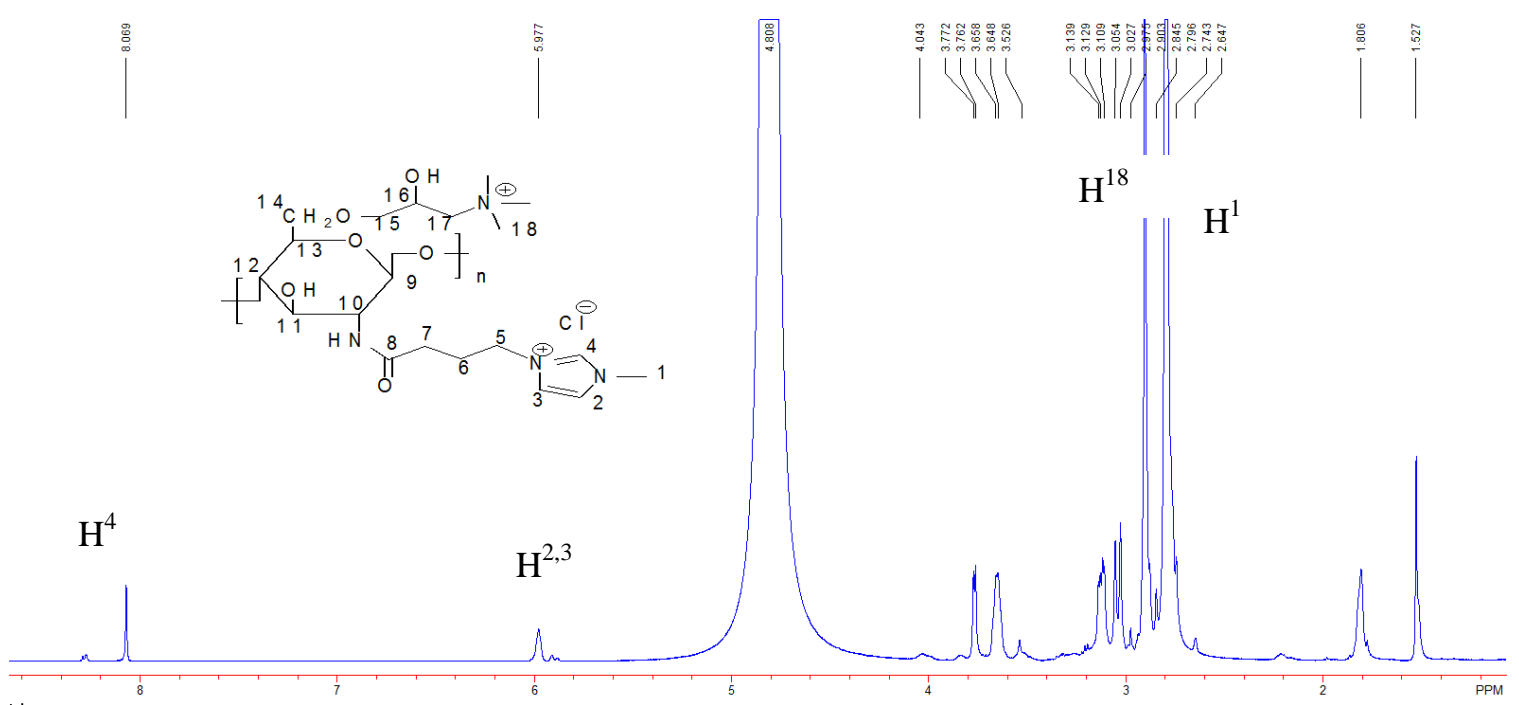




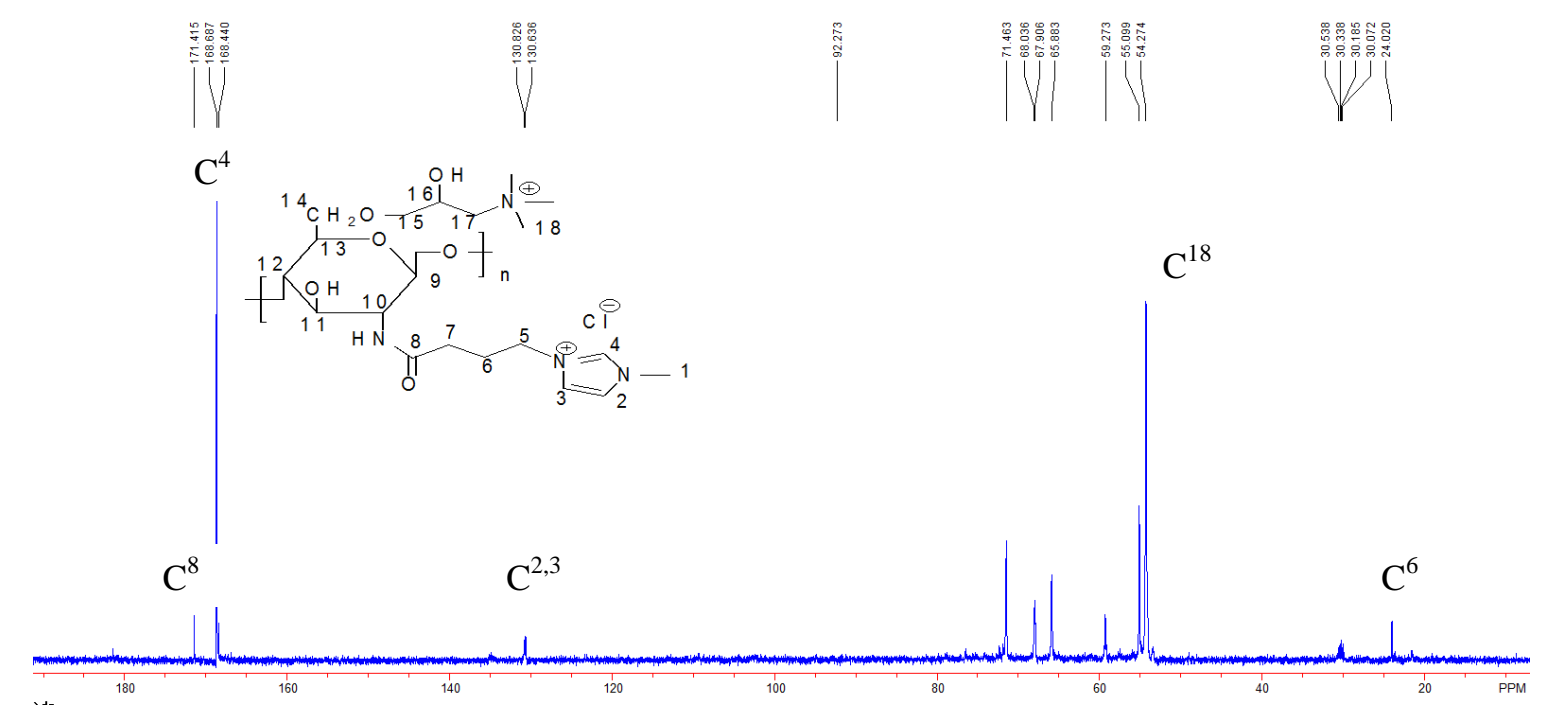

Figure $3 .{ }^{1} \mathrm{H}$ NMR and ${ }^{13} \mathrm{C}$ NMR spectra of Im-OHT-chitosan.

As a consequence, based on the data of UV, FT-IR, and NMR, it could be definitely concluded that $N$-methylimidazole and CTA groups were successfully introduced into the backbone of chitosan.

Molecular weight. Weight-average molecular weight (Mw) and number-average molecular weight $(\mathrm{Mn})$ of chitosan and its derivatives were measured by GPC, and the results were summarized in Table S1. The polydispersity (PD) data are determined by the ratio of $\mathrm{Mw}$ to $\mathrm{Mn}$ to be $1.062,1.069$, and 1.092 for chitosan, NHT-chitosan and ImOHT-chitosan, respectively, while Mw of them are 183735, 187662, and 170636, respectively. These data suggested that a series of samples fractions have narrow dispersity with similar molecular weight distributions.

\subsection{Antioxidant activity}

Reactive oxygen species (ROS) are chemically reactive molecules containing oxygen, including oxygen ions and peroxides. It is well known that excessive ROS may cause human diseases such as DNA damage, mutagenesis, and carcinogenesis, and even may be a major contributor to the functional decline that is characteristic of aging according to 
the free radical theory (Van Raamsdonk \& Hekimi, 2009; Cayuela 1995; Okezie 1998). To evaluate antioxidant activity of the chitosan derivatives obtained herein, we conducted three different kinds of in vitro antioxidant assays: hydrogen peroxide scavenging, hydroxyl radical scavenging and $\beta$-carotene-linoleate bleaching.

Scavenging activity on hydrogen peroxide. Hydrogen peroxide is a non-radical oxidant which is inevitable produced by the dismutation reaction in a biological system (including humans and bacteria). According to the previous reports, hydrogen peroxide is the most potent and reactive ROS species because it generates the hydroxyl radical, especially at the presence of transition metal ions (Jonas et al., 1989; Halliwell \& Gutteridge, 1984). Therefore, the measurement and search for the ideal antioxidant against hydrogen peroxide scavenging activity in food industry are important (Ozyurek et al., 2010).

As used in the most common UV-measurement method for the detection of $\mathrm{H}_{2} \mathrm{O}_{2}$, the scavenging capacity depends on the change of the absorbance at $230 \mathrm{~nm}$ when $\mathrm{H}_{2} \mathrm{O}_{2}$ is consumed by scavenger compounds. Hydrogen peroxide scavenging activities of NHT-chitosan, Im-OHT-chitosan, and the pristine chitosan are shown in Figure 4. At the initial reaction, the efficient degradation of $\mathrm{H}_{2} \mathrm{O}_{2}$ by all tested samples was observed. Both NHT-chitosan and Im-OHT-chitosan exhibited significantly enhanced hydrogen peroxide scavenging activity by comparison with pristine chitosan $(\mathrm{P}<0.05)$. Around $54 \%$ and $50 \%$ hydrogen scavenging activity were obtained for the Im-OHT-chitosan and NHT-chitosan, respectively, while that of pristine chitosan was only $10 \%$. 


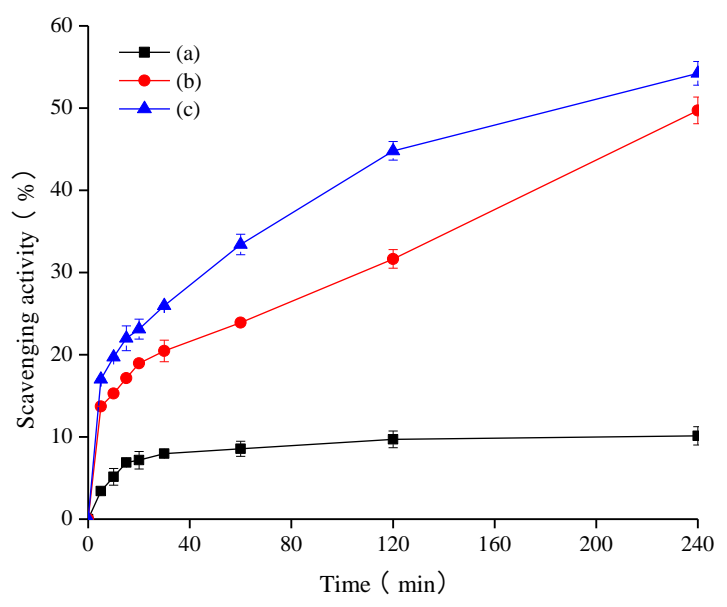

Figure 4. The scavenging activities of (a) chitosan, (b) NHT-chitosan, (c) Im-OHTchitosan against hydrogen peroxide.

$\beta$-Carotene-linoleate bleaching assay. It is well known that polyunsaturated fatty acids, such as linoleic acid, can be easily oxidized by oxygen in the air, thereby leading to the formation of aldehydes, ketones, acids, and alcohols, which are responsible for the changes in flavor, aroma, taste, and nutritional value (Lee et al., 2014). In the present study, the $\beta$-carotene-linoleic acid model system was used to evaluate the inhibition capacity of lipid peroxidation. As shown in Figure 5, the antioxidant activity of all samples was concentration-dependant. Im-OHT-chitosan and NHT-chitosan showed significant inhibition activity to $\beta$-carotene bleaching by comparison with pristine chitosan. Im-OHT-chitosan exhibited the highest inhibition capacity $(74 \%, 2.0 \mathrm{mg} / \mathrm{mL})$, followed by NHT-chitosan $(72 \%, 2.0 \mathrm{mg} / \mathrm{mL})$, and chitosan $(27 \%, 2.0 \mathrm{mg} / \mathrm{mL})$. 


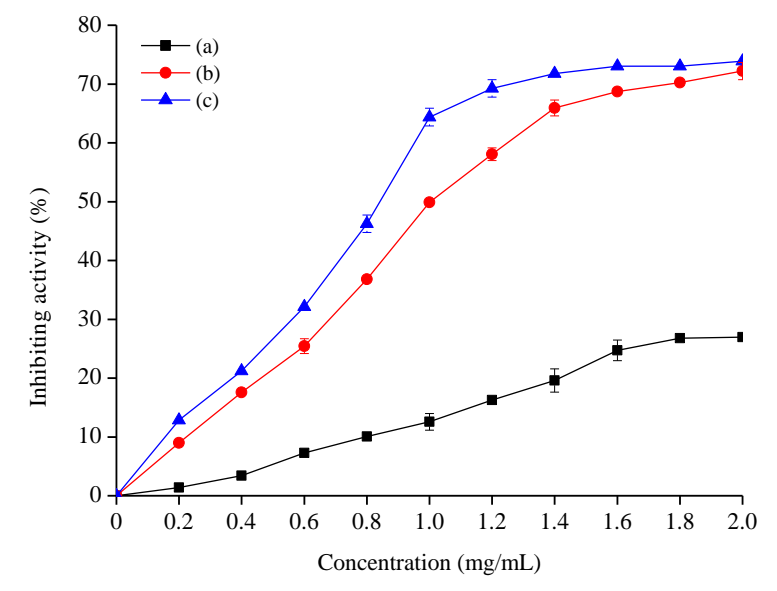

Figure 5. The inhibition activities of (a) chitosan, (b) NHT-chitosan, (c) Im-OHTchitosan against linoleic acid oxidation.

Hydroxyl radical scavenging activity. Hydroxyl radical $(\bullet \mathrm{OH})$ is the strongest reactive free radical, which can easily induce severe damage to a wide range of essential biomolecules (Cayuela 1995; Okezie 1998). The hydroxyl radical scavenging activity of chitosan, NHT-chitosan, and Im-OHT-chitosan are shown in Figure 6. Obviously, the hydroxyl radical-scavenging ability of NHT-chitosan and Im-OHT-chitosan is much higher than that of pristine chitosan at all concentrations. This result indicated that the scavenging activity of Im-OHT-chitosan significantly increased due to the synergic effect of the alien imidazole ring attached on the backbone of chitosan. At the concentration of $2 \mathrm{mg} / \mathrm{mL}$, the hydroxyl radical scavenging activity of Im-OHT-chitosan reached 66\% which was much higher than that of NHT-chitosan (35\%) and pristine chitosan (11\%). Notably, the measured value of the scavenging activity of NHT-chitosan against $\bullet \mathrm{OH}$ (35\%) was in accordance with the recent data reported by Mao group (30\%) (Huang et al., 2014) and by Li group (43\%) (Xing et al., 2008). 


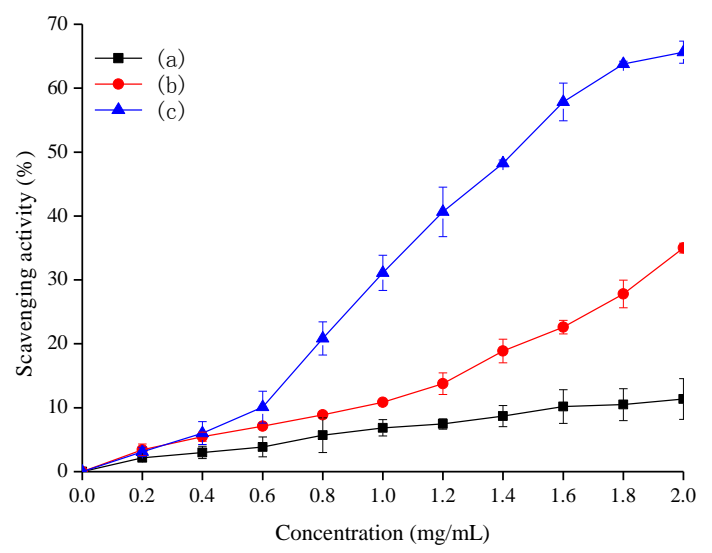

Figure 6. The scavenging activity of (a) chitosan, (b) NHT-chitosan, (c) Im-OHT-chitosan against hydroxyl radical.

The antioxidant activity of the chitosan and its derivatives mainly attributes to the active hydroxyl and amino groups, both of which have strong hydrogen-donating ability. Shon deduced that the clearance of hydroxyl radicals by polysaccharides are via two main mechanisms of (i) chelation with metal ions by alcohol hydroxyl groups against -OH formation, and (ii) cleaning hydroxyl radical by hydrogen-atoms of hydroxyl groups (Shon, 2003). NHT-chitosan has more hydroxyl groups than the pristine chitosan, thus exhibiting higher antioxidant ability. In the case of Im-OHT-chitosan, each imidazolium ring that was introduced onto the backbone of chitosan can easily leave 2 hydrogens of imidazolium out in the reaction system to form a carbene, so Im-OHT-chitosan showed the best antioxidant activity among all chitosans.

Chelation ability is important for the preservation of flavor and taste of food because the transition metal ions can initiate lipid peroxidation, then start a chain reaction and seriously deteriorate the quality of food. Previous studies demonstrated that chitosan, a long-chain polymer of $\mathrm{N}$-acetyl glucosamine could be used as a potential antioxidant 
agent because the active hydrogen atoms in hydroxyl or amino groups of chitosan could react with reactive oxygen species (ROS) to form a very stable macromolecular radical, and hydroxyl or amino groups could bind with transition metal ions, reducing the lipid peroxidation catalysis chance of metal ions.

Generally, antioxidant agents are able to prevent chain initiation, bind transition metal ions, decompose peroxides, and so on. Upon the results obtained above, the antioxidant activity of two (2-hydroxypropyl) trimethyl ammonium and/or imidazolebased quaternary chitosan derivatives (NHT-chitosan and Im-OHT-chitosan) was concentration-dependant, with the order of Im-OHT-chitosan > NHT-chitosan > pristine chitosan.

\subsection{Cathepsin D Inhibition}

As an aspartyl-type proteinase and a glycoprotein, Cathepsin D can be found in the cells and tissues of mammals ubiquitously (Zeece \& Katoh, 1989). Cathepsin D plays an important role during meat processing, which may finally influence meat tenderness and quality traits (Cafe et al., 2010; Godiksen et al., 2009). A number of myofibrillar proteins, such as titin and connectin, were found to be susceptible to hydrolysis by cathepsin D.It is essential for proteolysis of proteins to help in regulating cell growth and tissue homeostasis, which is expressed in most cells and over-expressed in breast cancer cells (Masson et al., 2011; Srivastava et al., 2006; Tandon et al., 1990), even involved in tumor metastasis (Ollinger, 2000; Lah et al., 1996; Rochefort et al., 1996). Nowadays, protease inhibitors have been traditionally developed from natural product screening for lead molecules with subsequent optimization (Chaturvedi et al., 2013), thus, chitosan-based cathepsin D inhibitor is a potential. 
Pepstatin $\left(K_{\mathrm{i}}=0.5 \mathrm{nmol} / \mathrm{L}\right)$ (Knight et al., 1976) is a specific and powerful inhibitor of cathepsin $\mathrm{D}$, which has been used to study the effect of endogenous proteases on meat aging (Alarcon-Rojo \& Dransfield 1995). Subsequently, substrate analogues containing statine and analogues of pepstatin have been synthesized and documented the cathepsin D inhibition with the $K_{\mathrm{i}}$ value varying from 1.1 to $100 \mathrm{nmol} / \mathrm{L}$ (Agarwal \& Rich, 1986). In this study, cathepsin D inhibition was assayed using a haemoglobin method. The results were presented in Figure 7. The cathepsin D inhibition activity of all samples exhibited dose-dependent. At the concentration of $2.4 \mathrm{mg} / \mathrm{mL}$, the inhibition activity of Im-OHTchitosan was 39\%, followed by NHT-chitosan (36\%), and chitosan (21\%). Compared to unmodified chitosan, Im-OHT-chitosan exhibited good inhibition activity toward cathepsin $\mathrm{D}$, implying that the introduction of imidazole group onto the backbone of chitosan played an important role in the behavior of cathepsin D inhibition activity. Upon the data of Lineweaver-Burk and Double-Dixon plot, the cathepsin D inhibition constant $\left(K_{\mathrm{i}}\right)$ of chitosan, NHT-chitosan, Im-OHT-chitosan was $6.48 \times 10^{-3} \mathrm{mg} / \mathrm{mL}, 3.65 \times 10^{-3}$ $\mathrm{mg} / \mathrm{mL}$ and $2.82 \times 10^{-3} \mathrm{mg} / \mathrm{mL}$, respectively. Competitive inhibition was observed for these three inhibitors.

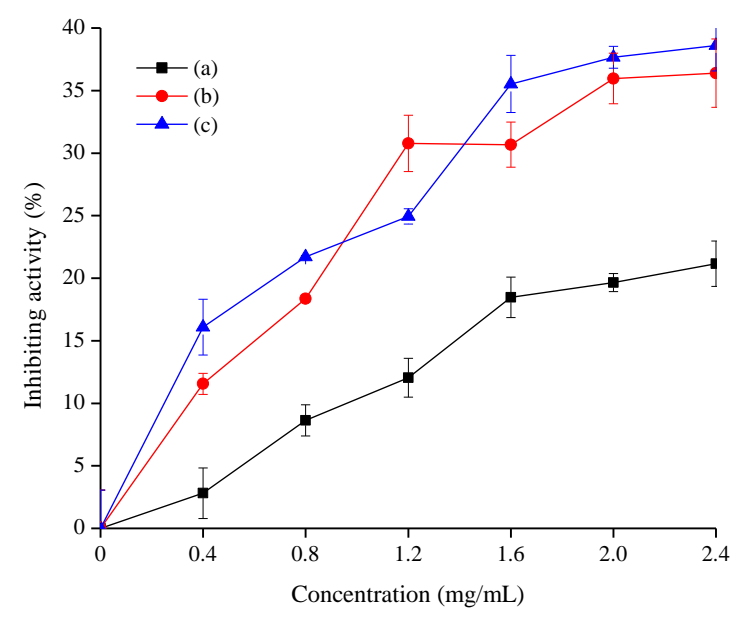


Figure 7. Cathepsin D inhibiting activity of (a) Chitosan, (b) NHT-chitosan, (c) Im-OHTchitosan.

It is well known that the polymers with different molecular weight have different functions, and chitosan has shown scavenging activity against different radical species due to the capacity of metal ions chelation (Aranaz et al., 2009). Herein, two quaternary chitosan derivatives, NHT-chitosan and Im-OHT-chitosan were obtained in mild reaction

conditions, thereby $\mathrm{Mw}$ were almost not changed compared with pristine chitosan. Nonetheless, Im-OHT-chitosan exhibited better antioxidant activity and cathepsin D inhibition activity than that NHT-chitosan and pristine chitosan did, indicating that the introduction of alien $N$-methylimidazole and (2-hydroxy-3-trimethylammonium)propyl groups played an important role in improving antioxidant activity and cathepsin D inhibition activity.

\section{Conclusion}

In this article, NHT-chitosan and Im-OHT-chitosan were synthesized and characterized. These two chitosan derivatives exhibited better antioxidant activities than the pristine chitosan, which indicated that the antioxidant ability of chitosan was strengthened by the introduction of alien $\mathrm{N}$-methylimidazole and (2-hydroxy-3-trimethylammonium)propyl groups to natural chitosan. Based on the data of scavenging against hydroxyl radical and hydrogen peroxide, the lipid peroxidation inhibition in the linoleic acid emulsion system, as well as the inhibition of cathepsin D protease activity, these synthesized quaternary ammonium chitosan derivatives exhibited highly efficient antioxidant activity and cathepsin D protease inhibition activity. They also can bind the iron atom in the center of myoglobin's heme group, thus reducing oxidation. NHT-chitosan and Im-OHT-chitosan 
may be potential and useful in applications as new healthy preservatives and antimicrobial reagents in the food and pharmaceutical industries.

\section{ACKNOWLEDGMENTS}

This study was supported by the Natural Science Foundation of Zhejiang Province of China (Y3110204), the Technology Planning Project of Zhejiang Province of China (2011C12031), the National Science Foundation of China (21102129), the Postgraduate Research Innovation Fund of ZJGSU (3100XJ1514147), and Food Science and Engineering of the most important discipline of Zhejiang province (JYTsp20142072).

\section{REFERENCES}

Agarwal, N. S.; \& Rich, D. H. (1986). Inhibition of Cathepsin D by Substrate Analogues Containing Statine and by Analogues of Pepstatin. Journal of Medicinal Chemistry, $1986,29,2519-2524$.

Alarcon-Rojo, A. D., \& Dransfield, E. (1995). Alteration of postmortem ageing in beef by the addition of enzyme inhibitors and activators. Meat Science, 41(2), 163-178.

Alves, M. N., \& Mano F. J. (2008). Chitosan derivatives obtained by chemical modifications for biomedical and environmental applications. International Journal of Biological Macromolecules, 43, 401-414.

Amin, I., Zamaliah, M. M., \& Chin, W. F. (2004). Total antioxidant activity and phenolic content in selected vegetables. Food Chemistry, 87, 581-586.

Aranaz, I., Mengíbar, M., Harris, R., Pãnos, I., Miralles, B., Acosta, N., Galed, G., Heras, A. (2009). Functional characterization of chitin and chitosan. Current Chemical 
Biology, 3, 203-230.

Aridoss, G., Balasubramanian, S., Parthiban, P., \& Kabilan, S. (2006). Synthesis and in vitro microbiological evaluation of imidazo(4,5-b)pyridinylethoxypiperidones. European Journal of Medicinal Chemistry, 41, 268-275.

Belalia, R., Grelier, S., Benaissa, M., \& Coma., V. (2008). New bioactive biomaterials based on quaternized chitosan. Journal of Agriculture and Food Chemistry, 56, $1582-1588$.

Bonilla, J.; Vargas, M.; Atarés, L.; \& Chiralt, A. (2014). Effect of chitosan essential oil films on the storage-keeping quality of pork meat products. Food and Bioprocess Technology, 7, 2443-2450.

Cafe L. M., McIntyre, B. L., Robinson, D. L., Geesink, G. H., Barendse, W., Pethick, D. W., Thompson, J. M., \& Greenwood, P. L. (2010). Production and processing studies on calpain-system gene markers for tenderness in Brahman cattle: 2. Objective meat quality. Journal of Animal Science, 88, 3059-69.

Calero, N., Muñoz, J., Ramírez, P., \& Guerrero. A. (2010). Flow behaviour, linear viscoelasticity and surface properties of chitosan aqueous solutions. Food Hydrocolloids, 24, 659-666.

Cayuela, M. M. (1995). Oxygen free radicals and human disease. Biochimie, 77, 147161.

Chao, A. C., Shyu, S. S., Lin, Y. C., \& Mi, F. L. (2004). Enzymatic grafting of carboxyl groups on to chitosan-to confer on chitosan the property of a cationic dye adsorbent. Bioresoure Technology, 91, 157-162.

Chaturvedi A. K., Luqman S., Dubey V., Thakur J. P., Saikia D., Chanotiya C. S., 
Shanker K., \& Negi A. S. (2013). Inhibition of Cathepsin D protease activity by Punica granatum fruit peel extracts, isolates, and semisynthetic analogs. Medicinal Chemistry Research, 22, 3953-3958.

Congio, C., Cocco, M. T., \& Onnis, V. (2008) Design, synthesis, and in vitro antitumor activity of new 1,4-diarylimidazole-2-ones and their 2-thione analogues. Bioorganic \& Medicinal Chemistry Letters, 18, 989-993.

Curcio, M., Puoci, F., Iemma, F., Parisi, O., Cirillo, G., Spizzirri, U. G., \& Picci, N. (2009). Covalent insertion of antioxidant molecules on chitosan by a free radical grafting procedure. Journal of Agriculture and Food Chemistry, 57, 5933-5938.

Esumi, H., Yasugi, S., Mizuno, T., \& Fujiki, H. (1980). Purification and characterisation of a pepsinogen and its pepsin from proventriculus of the Japanese quail. Biochimica et Biophysica Acta, 611, 363-370.

Godiksen, H., Morzel, M., Hyldig, G., \& Jessen, F. (2009). Contribution of cathepsins B, $\mathrm{L}$ and $\mathrm{D}$ to muscle protein profiles correlated with texture in rainbow trout (Oncorhynchus mykiss). Food Chemistry, 113(4), 889-896.

Halliwell, B., \& Gutteridge, J. M. C. (1984). Oxygen toxicity, oxygen radicals, transition metals and disease. Biochemical Journal, 219, 1-14.

Harikumar, P.; Ninjoor, V.; Warrier, B. S.; \& Kumta, U. S. (1974). Nitrite-induced inhibition of purified fractions of chicken muscle cathepsin D. Journal of Agricultural and Food Chemistry, 22, 530-532.

Harikumar, P., Ninjoor, V., Warrier, S. B., \& Kumta, U.S. (1974). Irreversible inhibition of chicken muscle cathepsin D by sodium nitrite. Indian Journal of Experimental Biology, 12, 32-4. 
Huang, J., Cheng, Z. H., Xie, H. H., Gong, J. Y., Lou, J., Ge, Q., Wang, Y. J., Wu, Y. F., Liu, S. W., \& Sun, P. L. (2014). Effect of quaternization degree on physiochemical and biological activities of chitosan from squid pens. International Journal of Biological Macromolecules, 70, 545-550.

Huang, X. Y., Bin, J. P., Bu, H. T., Jiang, G. B., \& Zeng, M. H. (2011). Removal of anionic dye eosin Y from aqueous solution using ethylenediamine modified chitosan. Carbohydrate Polymers, 84, 1350-1356.

Jonas, S. K., Riley, P. A., \& Wilson, R. L. (1989). Hydrogen peroxide cytotoxicity. Low temperature enhancement by ascorbate or reduced lipoate. Biochemical Journal, 264, $651-655$.

Knight, C. G., \& Barrett, A. J. (1976). Interaction of human cathepsin D with the inhibitor pepstatin. The Biochemical journal, 155, 117-125.

Krause, J., Tshidino, S. C., Ogawa, T., Watanabe, Y., Oosthuizen, V., Somai, B., Muramoto, K., \& Naude, R. J. (2011). Purification and partial characterization of ostrich skeletal muscle cathepsin D and its activity during meat maturation. Meat Science, 87, 196-201.

Kumar, M. N. V. R., Muzzarelli, R. A. A., Muzzarelli, C., Sashiwa, H., \& Domb, A. J. (2004). Chitosan chemistry and pharmaceutical perspectives. Chemistry Review, 104, $6017-6084$.

Lah, T.T., Calaf, G., Kalman, E., Shind, B., Somers, R., Estrad, S., Salero, E., Russo, J., \& Daskal, I. (1996). Cathepsin D, B, and L in transformed human breast epithelial cells. Breast Cancer Research Treatment, 39, 221-233.

Lee, D. S., Woo, J. Y., Ahn, C. B., \& Je, J. Y. (2014). Chitosan-hydroxycinnamic acid 
conjugates: Preparation, antioxidant and antimicrobial activity. Food Chemistry, 148, $97-104$.

Liu, J., Wen, X. Y., Lu, J. F., Kan, J., \& Jin, C. H. (2014). Free radical mediated grafting of chitosan with caffeic and ferulic acids: Structures and antioxidant activity. International Journal of Biological Macromolecules, 65, 97-106.

Liu, X., Chen, Q., \& Pan, H. (2007). Rheological behavior of chitosan derivative/cellulose polyblends from $\mathrm{N}$-methylmorpholine $\mathrm{N}$-oxide $/ \mathrm{H}_{2} \mathrm{O}$ solution. Journal of Material Science, 42, 6510-6514.

Liu, X. L., Xia, W. S., Jiang, Q. X., Xu, Y. S., \& Yu, P. P. (2014). Synthesis, Characterization, and antimicrobial activity of kojic acid grafted chitosan oligosaccharide. Journal of Agricultural and Food Chemistry, 62, 297-303.

Masson, O., Prebois, C., Derocq, D., Meulle, A., Dray, C., Daviaud, D., Quilliot, D., Valet, P., Muller, C., \& Liaudet-Coopman, E. (2011). Cathepsin D, a key protease in breast cancer, is up-regulated in obese mouse and human adipose tissue, and controls adipogenesis. PLoS ONE 6(2), e16452.

McLay, R. (1980). Activities of cathepsins A and D in cod muscle. Journal of the Science of Food and Agriculture, 31, 1050-1054.

Nagarapu, L., Satyender, A., Rajashaker, B., Srinivas, K., Rani, P. R., Radhika, K., \& Subhashini, G. (2008) Synthesis and antimicrobial activity of novel C-linked imidazole glycoconjugates. Bioorgic \& Medicinal Chemistry Letters 18, 1167-1171.

Nam, C. W., Kim, Y. H., \& Ko, S. W. (1999). Modification of polyacrylonitrile (PAN) fiber by blending with $\mathrm{N}$-(2-hydroxy)propyl-3-trimethylammonium chitosan chloride. Journal of Applied Polymer Science, 74, 2258-2265. 
Okezie, I. A. (1998). Free radicals, oxidative stress, and antioxidants in human health and disease. Journal of the American Oil Chemists' Society, 75, 199-204.

Ollinger, K. (2000). Inhibition of cathepsin D prevents free-radicalinduced apoptosis in rat cardiomyocytes. Archives Biochemistry Biophysics, 373, 346-351.

Ozyurek, M., Bektasoglu, B., Guclu, K., Gungor, N., \& Apak, R. (2010). A novel hydrogen peroxide scavenging assay of phenolics and flavonoids using cupric reducing antioxidant capacity (CUPRAC) methodology. Journal of Food Composition and Analysis, 23, 689-698.

Rabea, E. I., Badawy, M. E. T., Stevens, C. V., Smagghe, G., \& Steurbaut, W. (2003). Chitosan as antimicrobial agent: applications and mode of action. Biomacromolecules, 4, 1457-1465.

Reddy, P. R., Seenaiah, D., Padmaja, A., Padmavathi, V., \& Krishna, N. S. (2015). Synthesis, antioxidant, and cytotoxic activities of bis(oxazolyl/thiazolyl/imidazolyl)amidomethanesulfonyl Acetamides. Medicinal Chemistry Research , 24, 86-98.

Rochefort, H., Liaudet, E., \& Garcia, M. (1996). Alterations and role of human cathepsin D in cancer metastasis. Enzyme Protein, 49, 106-116.

Sashiwa, H., \& Aiba, S. (2004). Chemically modified chitin and chitosan as biomaterials. Progress in Polymer Science, 29, 887-908.

Sajomsang, W. (2010). Synthetic methods and applications of chitosan containing pyridylmethyl moiety and its quaternized derivatives: A review. Carbohydrate Polymers, 80, 631-647.

Sajomsang, W., Tantayanon, S., Tangpasuthadol, V., \& Daly, W. H. (2009). 
Quaternization of $\mathrm{N}$-aryl chitosan derivatives: synthesis, characterization, and antibacterial activity. Carbohydrate Research, 344, 2502-2511.

Schwartz, W. N., \& Bird, J. W. C. (1977). Degradation of myofibrillar proteins by cathepsins B and D. Journal of Biochemistry, 167, 811-820.

Shon, M. (2003). Antioxidants and free radical scavenging activity of Phellinus baumii (Phellinus of Hymenochaetaceae) extracts. Food Chemistry, 82, 593-597.

Siddiquee, K. A. Z., Gunning, P. T., Glenn, M., Katt, W. P., Zhang, S., Schroeck, C., Sebti, S. M., Jove, R., Hamilton, A. D., \& Turkson, J. (2007) An oxazole-based smallmolecule stat 3 inhibitor modulates stat 3 stability and processing and induces antitumor cell effects. ACS Chemical Biology, 2, 787-798.

Siripatrawan, U., \& Harte, B. R. (2010). Physical properties and antioxidant activity of an active film from $\mathrm{Ch}$ incorporated with green tea extract. Food Hydrocolloids, 24, 770-775.

Smith, R. C., \& Reeves, J. C. (1987). Antioxidant properties of 2-imidazolones and 2imidazol-thiones. Biochemical Pharmacology 36, 1457-1460.

Sobahi, T. R. A., Abdelaal, M. Y., \& Makki., M. S. I. (2014). Chemical modification of chitosan for metal ion removal. Arabian Journal of Chemistry. 7, 741-746.

Srivastava, V., Saxena, H. O., Shanker, K., Kumar, J. K., Luqman, S., Gupta, M. M., Khanuja, S. P. S., \& Negi, A. S. (2006). Synthesis of gallic acid based naphthophenone fatty acid amides as cathepsin D inhibitors. Bioorganic Medicinal Chemistry Letters, $16,4603-4608$.

Tandon, A. K., Clark,, G. M., Chamness, G. C., Chirgwin, J. M., \& McGuire, W. L. (1990). Cathepsin D and prognosis in breast cancer. New England J Medicine, 322, 
297-302.

Vachoud, L., Chen, T., Payne, F. G., \& Vazquez-Duhalt. R. (2001). Peroxidase catalyzed grafting of gallate esters onto the polysaccharide chitosan. Enzyme and Microbial Technology, 29, 380-385.

Van Raamsdonk J. M., \& Hekimi, S. (2009). Deletion of the mitochondrial superoxide dismutase sod-2 extends lifespan in Caenorhabditis elegans. PLoS Genetics, 5, e1000361.

Vasilatos, G. C., \& Savvaidis, I. N. (2013). Chitosan or rosemary oil treatments, singly or combined to increase turkey meat shelf-life. International Journal of Food Microbiology. 166, 54-58.

Xie, W., Xu, P., Wang, W., \& Liu, Q. (2002). Preparation and antibacterial activity of a water-soluble chitosan derivative. Carbohydrate Polymers, 50, 35-40.

Xing, R. G., Liu, S., Guo, Z.Y., Yu, H. H., Zhong, Z. M., Ji, X., \& Li, P. C. (2008) Relevance of molecular weight of chitosan-N-2-hydroxypropyl trimethyl ammonium chloride and their antioxidant activities. European Journal of Medicinal Chemistry 43, $336-340$.

Zavaleta-Aveja, L., Bosquez-Molina, E., Gimeno, M., Pérez-Orozco, J. P., \& Shirai, K. (2014). Rheological and antioxidant power studies of enzymatically grafted chitosan with a hydrophobic alkyl side chain. Food Hydrocolloids, 39, 113-119.

Zeece, M. G., \& Katoh, K. (1989). Cathepsin D and its effects on myofibrillar proteins: a review. Journal of Food Biochemistry, 13, 157-178.

Zhang, X., Geng, X. D., Jiang, H. J., Li, J.R., \& Huang J.Y. (2012). Synthesis and characteristics of chitin and chitosan with the (2-hydroxy-3-trimethylammonium) 
propyl functionality, and evaluation of their antioxidant activity in vitro. Carbohydrate Polymers, 89, 486-491. 